\title{
As Ciências e a Polícia
}

O ENSINO DA CRIMINALISTICA, FRENTE A MODERNA CONCEITUAÇÃO DE SUA DINĀMICA

EUGENIO LAPAGESSE

Diretor da Divisão de Operaçōes do Departamento de Polícia Federal

Estratificada por longos anos na simples constatação material das presenças, alça-se, a criminalística moderna, ao influxo da evolução de nossos tempos, já agora não apenas ao registro e análise dos indícios, mas também à sua interpretação, penetrando o domínio das relações e repercussões, o conhecimento da atualidade das hipóteses para a busca dos recursos científicos indispensáveis ao processo criador dos achados técnicos.

Descobrimos e aplicamos uma criminalística incipiente, tateante, quase de se dizer frustrada em seus primeiros passos, e ao cabo de nossas vidas, sedimentada, codificada em normas técnicas, transmitimos a nossos sucessores o conceito de um trabalho integrado e científico, a duras penas implantado na sua unidade nacional.

Fundamentada na pesquisa científica pura e aplicada, há que a criminalistica moderna multipartir-se nos diferentes campos das ciências, aos ramos de especializações aprofundadas, Q hão de os condicionamentos básicos que nos trouxeram das universidades de nossos tempos, estratificar-se em normas seletivas de alta objetividade, visando à libertação das amarras do convencionalismo profissional, à superação dos óbices da demorada seleção natural de que resultamos, para que de logo se lhe dê a necessária vivência de aplicação técnica e a busca de novos métodos e processos de definição.

Deverão predominar, nessa seleção, as fôrças de tendências pesquisadoras, analíticas, de formação cientifica, buscadas nos condicionamentos psicotécnicos, observadas as aptidões intrínsecas, as possibilidades de seu desenvolvimento, de par $\mathrm{com}$ um lastreamento intelectivo que permita rápida assimilacão dos conhecimentos profissionais específicos relativos ao 
âmbito da investigação pura e aplicada no campo geral das ciências, em todos os setores das atividades humanas, em tôda a forma incidente de transgressão às regras penais. E devem os valôres ser buscados num recrutamento amplo, de alta freqüência concorrente, possibilitando o treinamento de especialização em padrões acadêmicos e profissionais específicos cientificamente definidos, à base exclusiva do mérito, aí computada tôda a gama dos créditos sociais e personalistas.

Idealísticamente, êsse alistamento deverá se processar nas universidades, necessàriamente ao atendimento da lei da oferta e da procura, prevenindo-se remuneração consentânea de trabalho ao nível do grau universitário, tanto há que exigir-se alta preparação científica especializada e atividade integral.

$\mathrm{Na}$ realidade de hoje, a área de recrutamento é inferiorizada, e o surgimento do técnico com expressão de relêvo profissional se tem eivado de uma absurda consumição de tempo. O sistema prevalente só permite que através de sucessivos erros se forme o perito criminal, cujos conhecimentos apenas vêm a atingir maturidade ao término de sua vida funcional. $E$ isso, sabe Deus, a custa de quantos tropeços e que de ingente perseverança.

Se o problema é êsse, na sua magnitude, por que não produzir integração policial ao titular universitário? - Pela freqüência minima de tais solicitações, frente à restrição dos quadros funcionais; pela contingência da dedicação exclusiva, ante as peculiaridades do gênero de trabalho; pela incompensação econômica e, por fim, pela alta especialização que comporta, relegando os condicionamentos do exercício profissional básico. A rotina absorve-o, quase sempre o estratificando $\mathrm{em}$ faixa delimitada, em que the falecem os estímulos; encurta-seIhe o tempo da aplicação profissional de "Homem de Polícia", pela atividade profissional liberal ante a necessidade dos arranjos econômicos indispensáveis à sobrevivência social; torna-se uma burla a dedicação exclusiva.

Daí ressumbra a meridiana impossibilidade de se atrair pessoal competente em número expressivo, e a realidade de que o material da prova criminal vem a ser objeto de análise perfunctória, tateante, de um expert a que falta a junção, a simbiose da profundidade científica que acaso the sobre, com simbiose da profundidade científica que acaso lhe sobre, cò-
riamente lhe falte.

Aliás, a experiência tem demonstrado, à saciedade, que a posse de títulos universitários, quaisquer que sejam, não basta 
à integração profissional do perito criminal, eis êsses cursos se destinam a finalidades outras, não pertinentes à investigação criminal.

Tais títulos, pelos currículos escolares que ofereçam, poderão, subsidiàriamente, concorrer para sua formação; isoladamente, contudo, apresentam-se inoperantes e inadequados, obrigando complementação de ensino expressamente voltado para a pesquisa técnica específica da atividade profissional de polícia.

A mentalidade do cientista da polícia tem de ser estruturada pela inoculação de motivações típicas, que Ihe confiram a mais ampla visão dos fatos e uma forma característica de os enfrentar, na busca meticulosa da verdade, muita vez enrustida nos mais solertes artifícios.

Depois, qual o estímulo a radicar com exclusividade os profissionais da engenharia, da química, da medicina, da biologia, da farmácia, entre tantos outros, quando as solicitações liberais, de um país em pleno desenvolvimento tecnológico aí estão, pletóricas e compensadoras em relação ao funcionalismo público?

E ante a conjuntura, hão de ficar desvestidos os condicionamentos da defesa social?

E há de o crime sobrepor-se aos meios de seu combate?

Há compenetrarmo-nos de que, além das dificuldades expressas em fatôres imponderáveis, a luta contra a criminalidade vai se tornando tão complexa que não mais comporta bastar-se o homem na sua experiência e na sua intuição. Faz-se mister penetrar as leis do acaso no estudo das probabilidades, alargar as áreas dos conhecimentos tradicionais para a tomada das diretivas, ao sentido da interpretação ideal dos indícios, dos seus fatôres condicionados, dos métodos na relação de esfôrço e tempo, dos meios técnicos na aceleração estratégica dos objetivos, ponderados os valôres estatísticos das correlaçõeș dos acontecimentos aleatórios e os da análise dos riscos.

Cumpre-nos, assim, melhor que remediar na improvisação, prevenir os acontecimentos na linha de partida para a formação profissional específica do cientista da polícia, contornando, superando, eliminando as barreiras das restrições atuais, cujo inadimplemento conjuntural há conduzir à perplexidade da prova na evidenciação da ilicitude penal.

O perito criminal é o cientista da polícia, e, como tal, o homem chave da segurança pública. Nesse entendimento, há 0 imperativo de Ihe ser traçada a formação profissional especí- 
fica, e assim, ao lastro do conhecimento técnico-intelectivo, à intimidade das ciências, há integrá-lo, através da sucessão dos conhecimentos intrínsecos, no acrisolamento qualificado do legítimo homem de polícia. Há equacionar-se-lhe diretrizes (filosofia da razão de ser) e bases (política da condição de ser) na atribuição lapidadora do caráter profissional, cujo núcleo formativo deverá ter equivalência de unidade política e social, aos ditames dos princípios que lastreiam os ideais da solidariedade humana; da compreensão dos direitos e deveres profissionais do cidadão e dos diferentes grupos sociais, ao respeito da dignidade e liberdade fundamentais do homem contribuindo para o desenvolvimento integral da personalidade e para sua participação na obra da segurança pública, possibilitando o conhecimento e o combate aos antagonismos da evolução.

No trato da polícia científica, é ímpar a figura do perito criminal e somos por sua unidade profissional definida; por sua preparação específica, de nível universitário próprio, penetrando o campo do aprofundamento das técnicas nos seus domínios gerais, particularizadas nos condicionamentos das atividadesmeios, ao atendimento de suas peculiaridades, corrigindo a inversão dos propósitos que malsinadamente têm entravado a evolução técnico-científica do meio.

Senão, argumentemos com a documentoscopia, por exemplo, frente as suas múltiplas facêtas. E aí temos, antes da grafocinética, a morfo-fisiologia da escrita, penetrando os princípios da mecânica muscular, da fisiologia motora central, com suas implicações na motilidade inconsciente, subconsciente e consciente. O gesto gráfico, enfim, nas suas apropriadas condições fisiológicas de execução, no seu mecanismo geral e particular, abrangendo o gênero e a forma caligráfica em tôda a escala de suas implicações, da estrutura à precisão, dos condicionamentos do pêso gráfico, do jôgo dos claros-escuros; da velocidade em débito energético às disgrafias, ao relêvo final dos fenômenos grafopatológicos.

Aos seus fundamentos, seria a documentoscopia privativa dos diplomados da medicina, em cujos conhecimentos básicos se alicerça e de que se alça na interpretação da individualidade gráfica, dos próprios fenômenos da sua patogênese.

Mas a química tem aí, também, a sua vez. Não a química médica, mas a química analítica, mineral e orgânica, na qualificação e identificação dos papéis, na qualificação e identificação das espécies tintórias, na análise pura dos seus componentes físicos e químicos, na determinação da idade dos textos manuscritos. 
E havíamos, em consonância, buscar sábios paleógrafos ou profissionais da medicina e da química, que parodiando a estultícia econômica do nosso vezo, abandonando o campo geral das implicações profissionais enveredasse por êsse ramo da polícia científica? E haveríamos, pelo mesmo conseguinte, buscar oficiais militares que abandonando suas carreiras viessem a integrar o corpo dos peritos oficiais para solução dos problemas balísticos, ou algum armeiro como em eras priscas recomendava fôsse consultado o grande Chavigni? Físicos para, ainda só na documentoscopia, solucionar a problemática dos cruzamentos de traço? Químicos e engenheiros para os casos de explosões e de incêndios, para a perícia de máquinas infernais, quase sempre de confecção rudimentar? Médicos, biólogos, farmacêuticos, para os problemas da Hematologia Forense, dos locais de crime de sangue, enquanto para os de ocorrências de tráfego retornaríamos aos profissionais da engenharia, tantas as suas implicações?

Quantas outras observações a ressaltar, a aguardar surgissem essas tendências específicas do cultivo especializado da polícia científica, frente às solicitações impostas pelas contingências psicossociais do nosso País?

Dêsse antagonismo contingente, a nossa tese da unidade profissional no âmbito da criminalística.

Os especialistas nos diversos domínios da polícia científica, necessitam bastar-se em conhecimentos para buscar soluções adequadas aos problemas de sua especialização, sem que incidam na conceituação do exercício das diferentes profissões. Mas, evidentemente, à ênfase profissional, apenas na esfera Criminal, como parte integrante do órgão oficial a que se refere 0 art. 178 do Código Penal Brasileiro.

"No caso do art. 159, o exame será requisitado pela autoridade ao diretor da repartição, juntando-se ao processo o laudo assinado pelos peritos."

Requisitado ao diretor da repartição, órgão em que se congregam os peritos oficiais a que se refere o citado art. 178, o laudo não é, como um todo, dos peritos que o subscrevem, ainda que por êle responsáveis, como por seus atos oficiais são responsáveis os servidores públicos em geral, mas o ditame da repartição que o emite e expede. Tanto assim é, que o laudo

Nessa mesma tônica, que são, afinal, peritos oficiais? São aquêles servidores nomeados pelo Poder Executivo, para com- 
porem o Quadro Técnico da repartição a que se refere o citado art. 178.

É constitucional a forma de provimento dos cargos públicos - mediante concurso de títulos e provas.

São, assim, concursados os profissionais da criminalística que compõem os quadros de peritos criminais.

Ora, se ao amparo do $\S 1$ ? do art. 159 do Código referido

"Os exames de corpo de delito e as outras perícias serão em regra feitos por peritos oficiais.

$\S 1$ - Não savendo peritos oficiais o exame será feito por duas pessoas idôneas, escolhidas de preferência as que tiverem habilitação técnica",

pode ser perito qualquer pessoa idônea, e o servidor público 0 é até prova em contrário; com "preferência as que tiverem habilitação técnica", e essa é contingente aos peritos oficiais; assim, deviam estar êles, lidadores por excelência da diuturnidade da prova criminal, superlativamente credenciados ao seu processamento.

Mas, e aqui não vai nenhuma crítica, assim não o têm entendido doutos juízes; nesse sentido não é ditada a sábia jurisprudência dos Tribunais.

Em não havendo peritos oficiais, qualquer pessoa idônea poderá atender à indispensabilidade do exame de corpo de delito, à regra do art. 158 do mesmo Código.

"Quando a infração deixar vestígios, será indispensável o exame de corpo de delito, direto ou indireto, não podendo supri-lo a confissão do acusado."

e ao perito oficial não basta ser idôneo nem ter experiência técnica, deverá ter HABILITAÇÃO...

Mas, as ciências não são unidades herméticas, nem se constituem em monopólio de profissões.

De conseguinte, é mister, é preciso, e indispensável se situe a formação profissional específica do perito oficial, conduzindo-o ao inteiro domínio da criminalística na inteiração de seus fundamentos científicos, pela sistemática do ensino.

Já apontamos os percalços da seleção natural; é tempo de fazermos da criminalística uma profissão universitária, como ramo técnico especializado na aplicação das ciências. Lancemo-nos à formação de profissionais verdadeiramente aptos ao 
Seu desempenho, abolindo de vez a improvisação que até hoje vem imperando entre nós, ressalvadas honrosas exceções com graves e muitas vêzes irremediáveis prejuízos à salvaguarda do acusado inocente e do combate à criminalidade, hoje exercitada com requinte de perfeição no que concerne à dissimulação ou destruição dos vestígios.

Visando a formação do perito criminal, que sujeitaríamos à prova da investigação social a mais profunda e da análise psicotécnica, faríamos versar o exame seletivo sôbre matemática, física e química em nível acadêmico, além de conhecimentos gerais em outros ramos das ciências naturais e domínio de dois idiomas - espanhol ou francês; inglês ou alemão - sob as seguintes diretrizes:

MATEMÁTICA - Campo da análise matemática, compreendendo os estudos básicos dessa ciência, especialmente a aplicação de métodos de estabelecimento de equações de curvas e parte suplementar, em correspondência biunívoca, relativa ao cálculo diferencial, integral, vetorial e noções de cálculo tensorial. Geometria Analítica, cônicas e curvas de curvatura variável, em suas equações específicas e de definição.

FiSICA - Cinemática, hidrostática, dinâmica, acústica, ótica e eletricidade. Física dedutiva e matemática. Noções de física nuclear e eletrônica.

QUiMICA - Geral, mineral e orgânica. Estudo da natureza dos corpos; misturas, combinações e transformações passíveis de realizar. Reações dos elementos e sua identificação através de expressões analíticas adequadas.

MINERALOGIA - Classificação geral das espécies; minerais e minérios radioativos.

BIOLOGIA - No campo da botânica, a morfologia e sistemática, ou taxionomia; da zoologia, a sistemática das espécies mais patogênicas ao homem, embriologia; da histologia, o estudo e classificação dos tecidos; da citologia, o conceito geral; da genética, a introdução à genética humana.

Transposta a fase seletiva em todo o seu complexo, se Conveniente e oportuno em convênio com as universidades para o ensino das disciplinas gerais, condicionamento já relativamente superado pela Academia Nacional de Polícia em relação à Universidade de Brasília, penetrar-se-ia o azo da formação específica, que se segmentaria ao empenho do lastreamento indispensável ao sentido criminal de suas atividades e ao estabelecimento da doutrina mais consentânea às normativas éticas. 
Assim, partindo do geral para o particular, teríamos:

A) Fundamentos intelectivos. vidual e social.

I - PSICOLOGIA. Fundamentos gerais da psicologia indi-

II - SOCIOLOGIA. Calcado no conceito central de grupo, os aspectos gerais e estruturais dos grupos e sociedades; sua dinâmica, incluindo mobilidade, enfatizados os aspectos de desorganização ou patologia social.

III - ANTROPOLOGIA CULTURAL. Importância dos aspectos materiais, costumários, sociais e não materiais.

IV - PSICOPATOLOGIA FORENSE. O homem criminoso. Raízes psicológicas da criminalidade. A psicologia criminal individual e social. A testemunha. A vítima.

V - ESTATISTICA CRIMINAL. Finalidade. Colheita, arrumação e interpretação de dados. Criminalidade aparente. Análise dos fatôres antropológicos, físicos e sociais da criminalidade.

VI - LÓGICA E ESTUDO DAS PROBABILIDADES. Visando às regras do raciocínio correto nas últimas razões e causas, abordadas com as luzes do conhecimento para a disciplinação da busca da verdade. Análise dos circunstantes e viabilidades; racionalização.

VII - CRIMINOLOGIA. Estudo positivo do crime e do criminoso, aos fundamentos da antropologia, da sociologia, da biologia e estatística criminais.

VIII - ECONOMIA E FINANÇAS. Dada a importância basilar dos fenômenos econômicos do mundo de hoje, noções fundamentais sôbre valor e formação de preços, moeda e crédito, comércio internacional, macro-economia e desenvolvimento econômico, dando ênfase ao mecanismo da patologia social (fraude, falsificação, sonegação, contrabando e descaminho).

B) Fundamentos instrutivos.

I - FOTOGRAFIA. Ótica específica; relação de tons, contrastes. Côr e filtros. Prêto e branco e colorido. Ultravioleta $e$ infravermelho. Estereoscopia e estereofotografia. Macro e microfotografia. Química fotográfica.

II - MICROSCOPIA. Ótica. Microscópio químico, polarizador, de medidas, de comparação. Nefelometria. Micrômetros. Microprojetor. Microscopia eletrônica. 
III - FISICA FORENSE. Métodos físicos de análise. Instrumentos de medidas. Medidas físicas. Fontes luminosas. Refração. Ultravioleta e infravermelho. Raios X. Difração. Espectroquímica. Espectrofontometria.

IV - QUIMICA FORENSE. Hematologia. Sorologia. Técnica das manchas. Corantes. Tóxicos e entorpecentes. Papel. Tintas. Pólvoras e explosivos. Microquímica.

$V$ - ELETRÔNICA. Fundamentos, fontes de alimentação. Retificadores. Circuitos. Válvulas. Fluxo de escoamento. Amplificadores e transformadores. Osciladores. Transmissor. Modulação. Receptor.

VI - FISICA NUCLEAR. Elementos radioativos. Átomos traçadores. Energia atômica. Ação química radiante. Utilização dos elementos radioativos na pesquisa científica.

C) Fundamentos Profissionais.

i - de ordem geral.

I - DIREITO. (Constitucional, Administrativo, Leis Penais; Processo Penal). Filosofia. Princípios gerais. Infrações penais contra as instituições e em detrimento de bens, serviços ou interêsses da União.

II - ORGANIZAÇÃO JUDICIÁRIA E POLICIAL. Escalonamento dos órgãos nacionais e estaduais dos Podêres Judiciário Q Executivo pertinentes, com a mecânica de suas relações e os esquemas de entrosamento.

III - LEGISLAÇÃO POLICIAL. Sua tipificação. Privilégios e responsabilidades. Direitos e obrigações. Fundamentos éticos profissionais.

IV - IDENTIFICAÇÃO E DACTILOSCOPIA. Métodos. Retrato falado. Sistema datiloscópico de Vucetich; tipos fundamentais, pontos característicos, fórmula datiloscópica. Papiloscopia. Colheita e preservação de impressões em geral, em locais de infração penal. Montagem e organização de arquivos e prontuários. Arquivo Monodatilar e Palmar. Pesquisa. Perícia.

V - MEDICINA LEGAL. Fisiologia geral. Lesões corporais. problema médico-legal da morte. Questões de sobrevida. Locais de crimes de sangue.

VI - INFORMAÇÃO E SEGURANÇA. Conceituação e ciclo da Informação e Contra-Informação. Criptografia. Investigação especial de segurança. Espionagem, sabotagem e contra-sabotagem. Planejamento. Guerra Psicológica. Guerrilhas. 
VII - INVESTIGAÇÃO ESPECIALIZADA. Falsificações $e$ defraudações em geral. Moeda falsa; papéis públicos. Contrabando e descaminho. Tráfico de pessoas. Narcóticos. Crimes contra o Estado e a ordem política e social.

\section{operandi.}

VIII - TÁTICA DO CRIME. Repositório analítico dos modus

IX - CRIMINALISTICA GERAL. Relêvo dos indícios e evidências nos domínios da prova técnica; locais de crimes de sangue, de violência contra a coisa, desabamentos, incêndios, explosões, ocorrências de tráfego. Instrumentos. Preservação material e pesquisa técnica. Quesitos. Relatórios e laudos.

ii - de ordem especial.

I - MANCHAS, PÉLOS, FIBRAS, POEIRAS. Tecnologia da colheita de material e da análise. Sua valoração técnica. Interpretação conjuntural.

II - BALISTICA FORENSE. ARMAS E MUNIÇÕES. BOMBAS E EXPLOSIVOS. Pólvoras balísticas. Substâncias explosivas. Engenhos explosivos. Armas e munições. Balística interna, externa e de efeito. Ondas balísticas. Som.

III - DOCUMENTOSCOPIA. Moeda falsa; selos, comunicações secretas. Autenticidade; identidade gráfica; dinâmica das fraudes; padrões e peças-motivo; idade documental e seus correlatos.

IV - ESCOMBROS. Resistência dos materiais. Física dos sólidos. Combustiveis e comburentes. Substâncias explosivas e inflamáveis. Instalações elétricas. Incêndios; desabamentos. Causas. Perícia.

V - LOCAIS DE CRIME. Locais de crimes de sangue. LOcais de violência contra a coisa. Locais de ocorrências de tráfego. Dinâmica pericial.

Essa estrutura será sempre passível de atualização ao fluxo dos condicionamentos da evolução, tanto há a considerar 0 perito criminal, com vivência na intimidade da prova, participante ativo de sua descoberta, onde seu espírito, experimentado $e$ crítico, possa avalizar seus mínimos detalhes e, à percepção da escolha dos métodos, ao esteio de seus conhecimentos científicos, de sua técnica altamente especializada, conduzir-se para o alcance integrado de sua objetividade.

Têm, nessas considerações, especial cabida as cristalizadas, à luz da experiência de outros povos. O'Hora e Osterburg, do Corpo Diretor do Laboratório do Departamento de Polícia de 
Nova York, colocam o problema em evidência na Introdução à Criminalística, obra de todos nós conhecida, salientando que "E difícil estabelecer, com precisão, as qualificações que se exigem do cientista da polícia. As comissões de serviço civil tendem a ressaltar, em suas exigências para cientista forense, a importância de diploma universitário ou outro treinamento graduado especializado. Deve-se isso, talvez, à má compreensão do trabalho do laboratório de polícia. O criminalista deve esforçar-se por adquirir amplitude, bem como profundidade em sua educação científica. A pessoa sòmente especializada em Química ver-se-á incapaz de lidar com problemas elementares de Física ou Biologia. O trabalho do criminalista caracteriza-se pela grande variedade de assuntos relativamente elementares que precisa dominar. No local de crime, o cientista da polícia é essencialmente diagnosticador. Diante da prova do crime, êle deve indicar o significado dessa prova e esboçar os procedimentos através dos quais possa obter seu valor máximo. O conhecimento, embora titularmente credenciado, de parte limitada da ciência policial não toma o lugar do conhecimento geral dos muitos recursos dessa ciência."

Essas, as notas da nossa experiência, acumulada e sofrida na diuturnidade dos percalços que se nos antepuseram à realização do grande sonho da integração da Criminalística como um todo básico e autônomo na grande, na imensa tarefa do combate ao crime. 
